\title{
Digital text in the space of modern culture
}

\author{
Elena Severina*, Elena Milkevich \\ Southern Federal University, 344006, Rostov-on-Don, Russia
}

\begin{abstract}
The digital text within the domain of modern culture can be studied from the standpoint of the cultural-philosophical approach. It is based on M. Bakhtin's text-centric conception of dialogism and on the post-structuralism practice of text deconstruction in the conceptions by $\mathrm{J}$. Derrida and R. Barthes. The theories of these scientists reveal some basic principles how to understand the digital text phenomenon and what methods to apply in the analyses of these new cultural practices in the space of digital culture. The reduction of cultural information down to a "digital code" determines the dual logic of the text (the logic of culture and digital logic), which should become the subject of focused cultural studies. The notion of hypertextuality plays a special role in the understanding of the digital text, and the deconstructive practice of reading-writing is considered as a kind of the reader's 'material intervention' into the text. It makes the digital text an ongoing autocommunication of the AuthorReader. This process is grounded on the computer interface metalanguage or cultural metalanguage, which organizes the digital text information in a specific way and influences both the functioning of the text as a cultural object and the way it is perceived by the user.
\end{abstract}

\section{Introduction}

The modern era of social value transformations is more often called the "digital cultural turn" (Chernenkaya, 2018, p. 58) due to the large-scale spread of digital technologies. The formation of cultural experience and the generation of senses in modern culture take place largely in the environment of computerized and virtualized communication processes. As a result, the borderline "between humanitarian and technical cultures" (ibid.) is blurred, and it leads to the emergence of new objects for humanitarian research - social media texts, videos on video hosting sites, net communication, etc . In order to study the ongoing processes in culture, to solve new problems related to the impact of the digital environment on the social and humanitarian sphere researchers need new interdisciplinary scientific approaches. Having combined the methodology of the Humanities with methods of computer sciences we can speak about joint methods of Digital Humanities (DH) in general.

\footnotetext{
*Corresponding author: emkovalenko@sfedu.ru
} 
As the language is the most important element of the culture semiotic system, the problem of cultural-philosophical understanding of the text in the space of digital culture becomes crucial for the whole understanding of modern socio-cultural processes. On the other hand, the digital culture cannot be separated from a 'non-digital' one. Therefore studying the influence of digital technologies on the sociocultural sphere requires focusing not only on the study of the digital culture itself, but also on 'non-digital' and 'pre-digital' cultures, all of which are interconnected and thus interact (Sokolova, 2012, p. 10).

\section{Research methodology}

The methodological basis of the research is the cognitive approach to culture and interdisciplinary methods of DH as part of general scientific methodology. The basis of the content of the study is represented by the analysis of cultural-philosophical conceptions of the text in the context of cultural and language interaction. These conceptions had had a significant impact on the very understanding of the text in the digital era. The research also uses analytical and comparative approaches, conceptual and structural-semiotic analyses.

\section{Text as a universal form of culture}

M. Bakhtin was one of the first who suggested that the text is a universal category of culture. In his theory the text is viewed as a phenomenon that goes beyond the linguistic framework, i.e. as a generalized and objectified form of human communication. Consequently, the interpretation of the text occurs through its correlation with its cultural context and is based on the conception of dialogue (between cultures, minds or personalities). This dialogical interaction is carried out in the text and at the same time goes beyond and actually occurs in communication and human activity in general. Such understanding makes it possible to consider the text as a product that includes an "extratextual intonation value context", i.e. as a dialogue immersed in the endless cultural context of the author's and the reader's personalities. Moreover, the actual meaning of the text is always marked by some lack of understanding due to the natural duality of the process, which originates from individual inner senses and the sets of social meanings of the interlocutors (Kovalenko et al., 2016, p. 27-28). Expanding the text to the dimensions of a cultural object, M. Bakhtin places it beyond the limits of local cultures, which are understood as dialogical self-consciousness of each civilization embodied in a complex, hierarchically organized set of texts. This view on the text formed the basis of the idea of "intertextuality", which was developed in postmodern studies and got further implementation in the era of digital hypertexts.

In the postmodern interpretation, the text appears as some conceptualized space or intertext, which basically has no author, but whom the text generates. In such understanding, culture, thinking processes and reality are "textualized", so the ambiguity of any meaning is turned into a methodological principle.

G. Derrida considers the text as a complex heterogeneous formation coming out as a result of appearing and interaction of various semiotic spaces. This formation is characterized by multiplicity and intertextuality, is created from other texts and have the ability to generate new meanings. In a situation of loss of meaning, the whole world becomes an infinite, limitless cultural text or an ideological phenomenon of written culture - "there is nothing outside the text" (Derrida, 1997, p. 158). 
The ideas of J. Derrida had a great influence on the formation of the postmodern paradigm, in which the text rejects any transcendence, asserts cultural discourse, textualizes reality and blurs boundaries between the languages of culture. J. Derrida interpreted language as education immanent to reality, therefore the poststructuralist method of philosophical reflection is based on deconstructive methodology and cognitive imperative of "postmodern sensitivity". Thus, a non-linear way of postmodern cognition of the world is asserted, in which the deconstruction of reality takes place through text deconstruction.

R. Barthes explained the deconstructional semiological practice of "reading-writing" as the process during which the text is reconstructed from the elements interacting with the reader's consciousness (which is also represented by a multitude of texts). With the help of this idea he tried to destroy the power of ideological myth as a specific semiotic phenomenon. As a result, the postmodern understanding of the text was formed. The text is actually an intertext, a "methodological field", which results from "overturning of previous categories" and exists only in discourse (Barthes 1979, p. 74). In other words, the postmodern text is an ideological atmosphere of culture, which manifests itself in any text independently of its author.

\section{Culture Digitalization: Digital Text}

Digital transformation of modern culture means that cultural practices occurs into the mode of digital production and distribution of any cultural objects, organization of communication with the help of computer technologies. As a result digital technologies in today's culture mostly act as "metamedium" (Manovich, 2001, p. 33) in the transmission of human experience and human interaction with reality. Changes in the way how information is processed affect the specifics of the text existence, its digitalization distorts both the textual reality and a person's interaction with it, which in its turn requires a rethinking of the text within the context of various levels of its existence in the 'digital' format.

In order to understand the logic of the meaning production in modern computerized culture, it is necessary to turn to the study of the principles how the technology of digital space functions today. The modern text existing today in the digital environment is, first of all, a screen text generated by a computer interface that also functions as a cultural representation, i.e. as a "cultural interface" (Manovich, 2001, p. 79).

Lev Manovich, describing the phenomenological nature of new types of media, also including the digital text, introduces the concept of cultural transcoding (Manovich, 2001, p. 63), which makes it possible to explain that the structure of the digital text is based on two logics - on the logic of culture recognized by man and on logic of computerized information organization. The digital text can be not only read and understood by humans, but also automatically processed using computer technologies. So, both traditional methods of research (hermeneutic, phenomenological, literary analysis, etc.) and methods of mathematical and computer analysis (NLP methods) can be applied to study the digital text.

The process of digitalization of any object is decisive for creation of a digital environment. It causes the reduction of cultural information to a "digital code" (Manovich, 2001, p. 49), i.e. information in different material media undergoes the process of "flattens" through coding (Manovich, 2001, p. 49), which allows the text, while acquiring new qualities of the digital environment, to interact more closely with other cultural objects images, videos, etc. The new materiality of the text also affects the principles of its perception, dictated by the digital interface, which forms new physical and motor habits, changing the rules for creating and working with verbal texts (Maslenkova, 2012, p. 74). 
The principle of digitalization largely determines the functioning of the text both at the level of the cultural logic of its creation and perception, and at the level of input/output on digital devices.

Digital forms of text existence generate new cultural practices, one of which is the hypertext, a form of information transfer through linear and non-linear reading and an embodiment of the postmodern idea of intertextuality. The digital hypertext embodies the postmodern idea of the author's 'death', when the reader not only deconstructs the original meanings, but makes "material intervention" into the text, participating in organizing information and becoming a prosumer (a content producer and a content consumer simultaneously) (Chernenkaya, 2018, p. 60 ). It leads to the convergence of the author and the reader in a digital hypertext, i.e. the digital text, like all new media in general, changes the interaction between the author and the audience, whose activity is determined not only by the perception and interpretation of the information received, but also by the opportunity to become an active participant in the process of producing and distributing content and to create your own "low-level media" (Sokolova, 2012, p. 7).

Cultural verbal tradition has always been associated with rhetorical practices, but the rhetorical means in the hypermedia era narrow down to one device, metonymy (Manovich, 2001 , p. 86), because the hypertext makes the reader endlessly 'glide' from one text to another, turning a digital culture into an endless surface on which separate texts are randomly located. Digital media implement the postmodern preference for the category of space over the category of time "time becomes a flat image or a landscape" (ibid.). It determined the connection between rhetoric and aesthetics of digital culture with the development of spaces. A digital person "leaving imprints in the sand, which, like computer hyperlinks, follow from one found object to another" (Manovich, 2001, p. 87).

The user interacts with the text in the digital environment indirectly through a computer interface that acts as a key semiotic "code which carries cultural messages in a variety of media" (Manovich, 2001, p. 76). As a 'participant' of the cultural communication process, the interface cannot remain 'neutral', it affects messages and constructs "its own model of the world, its own logical system, or ideology" (ibid.), i.e. the interface using a technology filter system represents the user indistinguishable for him digital information based on its own logic. It influences the functioning of the text as a cultural object and its perception by the user. The interface has a cognitive "metaphorical logic" (Manovich, 2001, p. 80), which it uses to create representations, simulate the human perception of information or to replace some of the human cognitive patterns by processing incoming signals from outside. Such a replacement simplifies the processing of information which is redundant, repetitive, or inaccessible to humans by conducting a selection of incoming signals and forming habitual behavioral patterns. It enables to process large amounts of information and identify its hidden structures. However, formed patterns can be used both to organize human interaction with the text and other cultural objects (from reading to writing), and to achieve specific goals against his will, because the interface is always teleological (Rodionova, 2019, p. 95).

The text plays a special role in digital culture, representing, on the one hand, the metalanguage of digital data, and on the other, the main means of interaction between a person and a computer that uses the text as the metalanguage. Therefore, cultural interfaces genetically go back to "the principles of text organization developed by human civilization" (Manovich, 2001, p. 84). A computer page is one of such specific forms of organizing information. At the same time, cultural interfaces attempt to expand and rethink the logic of the "page interface" by using new concepts, for example, a virtual page, "a surface which can be much larger than the limited surface of a computer screen" (ibid.), including 
hypertext marking and distribution of document elements on different computers. As a result, it became possible to embed different types of media graphics, photos, videos, etc. into the body of the text, so that one page interface can combine several different approaches to organizing the process of reading the text, intertwining several cultural traditions. Besides, the hypertext content organization on the page de-hierarchicalizes any interaction on the page and forms collage aesthetics when "radically different sources are brought together within the singular cultural object ('post-modernism')" (Manovich, 2001, p. 85).

Cultural interfaces of digitalized reality create their own language, attempting to find common properties between metaphor and methods of "controlling a computer", traditional cultural genres and ways of producing cultural meanings, i.e. a new cultural meta-language is formed, that "can keep on changing forever" (Manovich, 2001, p. 97-98) due to changes in the ways of production and distribution of digital data.

\section{Conclusion}

The text for M. Bakhtin is a universal category of culture; it defines culture and is based on dialogue. M. Bakhtin's idea of "intertextuality" was further developed in postmodern studies and implemented in the modern era of digital hypertexts.

The digital text is, in the first place, an on-screen text generated by a computer interface that relies on "the principles of text organization developed by human civilization" (Manovich, 2001, p. 84).

The concept of hypertextuality has a special meaning for screen texts, since the digital environment create a new practice of working with texts - the deconstructive practice of reading-writing moves to the level of the reader's "material intervention" into the text. The Author and the Reader are combined, and the digital text becomes an endless auto-dialogue of the Author-Reader, mediated by the logic of the computer interface, the language of which acts as a new cultural metalanguage. This metalanguage is subjected to constant changes and has a great influence on the perception and methods of representation of the digital text, organizing information in a certain way.

In the digital space, the reduction of cultural information to a "digital code" determines the double logic of the text (the logic of culture and digital logic), which should become the specific subject of cultural studies. Such understanding of the text opens up new opportunities for language and cognition analyses in the space of digital culture, the influence of the digital environment on the social and humanitarian sphere.

\section{References}

1. R. Barthes, From Work to Text, Textual Strategies: Perspectives in Poststructuralist Criticism, 73-81 (Ithaca, Cornell University Press, 1979).

2. S.V. Chernenkaya, Text in the Digital Culture Space (Vestnik of Moscow City University, Philosophical Sciences, 3 (27), 58-63 (2018).

3. J. Derrida, Of Grammatology (John Hopkins University Pres, Baltimore, 1997).

4. E.M. Kovalenko, M.V. Laskova, V.A. Lazarev, M.V. Ivchenko, N.G. Nosoreva, Text as a Cognitive Form of Culture, The International Journal of Interdisciplinary Cultural Studies, 11 (3), 25-32 (2016). 
5. L. Manovich, The Language of New Media (The MIT Press Massachusetts, London, England, 2001).

6. N. A. Maslenkova, Reader + Viewer $=$ ? - On the new Text Comprehension Practice, International Journal of Cultural Research, 3 (8), 74-79 (2012).

7. A.A. Rodionova, Antinomy of text in the interface: Continuity and discreteness, The Digital Scholar: Philosopher's Lab, 2 (1), 88-99 (2019).

8. E.M., Severina, S.G. Agapova, Y.S. Milkevich, E.A. Agapova, Culture as a Cultural Concept within the Cognitive Context, International Journal of Interdisciplinary Cultural Studies, 13 (1), 15-28 (2018).

9. N.L. Sokolova, Digital Culture or Culture in the Digital Age? International Journal of Cultural Research, 3 (8), 6-10 (2012). 